\title{
Editorial: 2 Years of Journal of Cognitive Enhancement
}

\author{
Lorenza S. Colzato ${ }^{1,2}$
}

Published online: 15 March 2019

(C) Springer Nature Switzerland AG 2019

Just like with people, the continuing identity of a journal emerges through change. The changes that this journal will see in 2019 refer mainly to the editorial board. It is time to say a warm "thank you" to Heleen Slagter, Roberta Sellaro, and Stefanie Enriquez-Geppert, who did a great job in moving the journal forward in the past 2 years. Since January 2019, we are welcoming three new associate editors: Franziska Plessow, Anna Wexler, and Marieke van der Vugt — three excellent scientists who will be able to keep the journal's high quality and open-minded attitude alive.

The second year of Journal of Cognitive Enhancement included a broad overview of theory-driven cognitive enhancing articles ranging from resistance training (Soga et al. 2018), meditation (Zanesco et al. 2018), psychoactive stimulants (Graczyk et al. 2018), genetic editing (Lavazza 2018), and brain stimulation (Di Nuzzo et al. 2018). We published two exceptional special issues dedicated to physical exercise edited by Louis Bherer, Art Kramer, and myself (issue 2, volume 2) and neuroethics edited by Andrea Lavazza and myself (issue 2, volume 4).

Regarding the current issue, one article caught my attention: the consensus paper by Shawn Green et al. (2019) about how to improve methodological standards in behavioral interventions for cognitive enhancement. This consensus article represents the joint effort of 48 eminent scientists in order to find explicit and widely agreed upon consensus around the best methodological practices. The take of this consensus paper is very original because it starts from the perspective that there are many types of studies that are important in this domain - e.g., feasibility, mechanistic, efficacy, and effectiveness. These studies have fundamentally different goals, and,

Lorenza S. Colzato

colzato@fsw.leidenuniv.nl

1 Institute for Psychological Research and Leiden Institute for Brain and Cognition, Leiden University, Leiden, The Netherlands

2 Institute for Psychological Research, Cognitive Psychology Unit, Leiden University, Wassenaarseweg 52, 2333, AK Leiden, The Netherlands as such, the best-practice methods to meet those goals will also differ. Accordingly, this consensus paper makes suggestions in topics ranging from the design and implementation of control groups, to reporting of results, to dissemination and communication, taking the perspective that the best practices are not necessarily uniform across all study types.

Along the lines of 2018, we will keep looking for interesting special issues; please let us know about any thoughts you might have on these topics.

Let me conclude by thanking all our loyal readers and authors and, of course, all our enthusiastic reviewers, who are so essential for maintaining the journal's high quality.

\section{References}

Di Nuzzo, C., Ferrucci, R., Gianoli, E., Reitano, M., Tedino, D., Ruggiero, F., \& Priori, A. (2018). How brain stimulation techniques can affect moral and social behaviour. Journal of Cognitive Enhancement, 2(4), 335-347.

Graczyk, A. M., Ziegler, A. M., Bendlin, A., Sion, T., Vattana, K., \& Temple, J. L. (2018). Effects of caffeine administration on reaction time, attention, and inhibitory control in children and adolescents. Journal of Cognitive Enhancement, 2(3), 276-286.

Green, C. S., Bavelier, D., Kramer, A. F., Vinogradov, S., Ansorge, U., Ball, K. K., et al. (2019). Improving methodological standards in behavioral interventions for cognitive enhancement. Journal of Cognitive Enhancement. https://doi.org/10.1007/s41465-018-0115-y.

Lavazza, A. (2018). Cognitive enhancement through genetic editing: A new frontier to explore (and to regulate)? Journal of Cognitive Enhancement, 2(4), 388-396.

Soga, K., Masaki, H., Gerber, M., \& Ludyga, S. (2018). Acute and longterm effects of resistance training on executive function. Journal of Cognitive Enhancement, 2(2), 200-207.

Zanesco, A. P., King, B. G., MacLean, K. A., \& Saron, C. D. (2018). Cognitive aging and long-term maintenance of attentional improvements following meditation training. Journal of Cognitive Enhancement, 2(3), 259-275.

Publisher's Note Springer Nature remains neutral with regard to jurisdictional claims in published maps and institutional affiliations. 